\title{
A minimally invasive approach to transperitoneal perforation of the bladder during bladder fumour resection
}

\author{
Mena Bishay, MD; R. John D'A. Honey, MD² \\ 'University of Alberta, Edmonton, AB, Canada; '2University of Toronto, Toronto, ON, Canada
}

\section{Abstract}

The authors present a case of intraperitoneal rupture of the bladder during transurethral resection of a bladder tumour (TURBT), which was managed conservatively. By passing a urethroscope - which was smaller in diameter than the perforation - through the hole, a small superficial burn was identified on the adjacent bowel and deemed benign, saving this patient with multiple comorbidities from having to undergo an open laparotomy. The bladder was drained with a Foley catheter to allow the perforation to heal and the patient was discharged without incident. By using this approach, a direct view of the neighbouring structures confirmed the integrity of bowel and prevented the need for increased risks associated with a laparotomy.

\section{Introduction}

Transurethral resection of a bladder tumour (TURBT) is the standard approach to staging and treating bladder tumours. ${ }^{1-4}$ One procedural risk is bladder perforation. This is more frequently extraperitoneal, but rarely may be transperitoneal, with possible negative sequelae. Balbay et al demonstrated that up to $58 \%$ of TURBTs resulted in contrast extravasation through small and otherwise asymptomatic extraperitoneal perforations. ${ }^{5}$ There is no information on the incidence of intraperitoneal perforation. With intraperitoneal perforation, there is a risk of bowel injury. If intraperitoneal perforation is recognized, the current standard is to proceed with an open laparotomy to rule out bowel injury and to close the bladder perforation. ${ }^{6}$ However, this invasive approach may lead to other complications and increased length of hospitalization. These additional risks merit exploration of less invasive options. Laparoscopic repair of iatrogenic intraperitoneal bladder perforation has previously been reported as a more conservative alternative to open laparotomy. ${ }^{7,8}$ Passing the resectoscope through the perforation and using this to guide the percutaneous placement of a pigtail drain has also been described. ${ }^{9}$

We would like to present a case in which a small 20F zero degree urethroscope was passed through a perforation created during TURBT to inspect the adjacent bowel for possible injury and to avoid an open laparotomy.

\section{Case report}

A 64-year-old obese man presented with a nine-month history of intermittent, painless hematuria. An ultrasound ordered by his family physician showed a $3.8 \mathrm{~cm}$ hypervascular mass on the posterior bladder wall. The patient is an insulin dependent diabetic with chronic kidney disease, peripheral vascular disease with a previous right above knee amputation, hypertension, hypercholesterolemia, and coronary artery disease with two coronary artery stents.

Flexible cystoscopy demonstrated a $4 \mathrm{~cm}$ diameter papillary bladder tumour on the left posterior bladder wall. A TURBT was performed, followed by bilateral retrograde pyelograms, which identified no upper tract filling defects. Pathology revealed a high-grade papillary urothelial carcinoma with stromal and possible vascular invasion. Significant cautery artifact of the muscularis propria made invasion of the detrusor muscle difficult to assess.

After discussing the results with the patient, a re-resection was performed with a $24 \mathrm{~F}$ monopolar continuous flow resectoscope. At the end of the resection, a deeper resection biopsy was performed in the middle of the scar to include detrusor muscle, but a full thickness perforation was created through to the peritoneal cavity. Instead of proceeding directly to a laparotomy in this obese man with numerous comorbidities, we used a smaller 20F zero degree urethroscope to look through the perforation. This passed through without enlarging the perforation. We used minimal irrigation and obtained an excellent view of the bowel adjacent to the perforation. One small superficial crescent-shaped cautery mark, the shape of the resectoscope loop, was seen on the anterior rectal wall. We requested the opinion of a general surgeon, who visualized the injury clearly and agreed this was a minor serosal burn, which would not need to be oversewn. The $6-8 \mathrm{~mm}$ hole was clearly too 
small for abdominal contents to pass through, and as the bladder was emptied, the edges of the hole contracted and opposed each other.

After hemostasis was achieved, a 22Fr two-way Foley catheter was inserted and attached to straight drainage with orders to irrigate the catheter with $10 \mathrm{ml}$ sterile saline should there be no drainage for one hour. The catheter drained clear urine and did not require irrigation. The patient was kept in hospital for observation for 48 hours without incident. After 10 days, a cystogram demonstrated a normal-appearing bladder without evidence of extravasation, and the catheter was removed.

Pathology of the reresection showed a small area of residual high-grade urothelial carcinoma with invasion to the lamina propria, but no involvement of the muscularis propria.

\section{Discussion}

TURBT is a common procedure performed by most urologists. As such, it is important that urologists can appropriately manage any complications.

In an attempt to obtain adequate detrusor muscle to assess the depth of invasion, perforation of the lateral wall into extravesical fat may occur. This is managed with catheter drainage. Perforation of the posterior wall or dome is rare. All urologists are aware that perforation in these areas will result in a hole into the peritoneal cavity. Great care is therefore taken with a careful, shallower resection. As the bowel loops lay up against the peritoneal surface of the bladder, a full thickness perforation can result in a bowel injury.

The standard approach to an intraperitoneal bladder perforation during TURBT is an immediate laparotomy to exclude a bowel injury and repair the bladder perforation. This would have been a morbid procedure in this obese patient.

Where laparoscopy has previously been used, closure of the perforation is straightforward. However, examining the bowel is difficult laparoscopically and the injury can be missed. The advantage of the minimally invasive approach we describe is that there is an excellent view of the bowels directly behind the perforation before they move or are disturbed. A small 20F scope passes through the perforation easily, as the hole is larger having been made with the $24 \mathrm{~F}$ loop of the resectoscope.

Small perforations, such as occurred in this case, collapse and appear to close with an empty bladder. This should heal with catheter drainage for 10 days, as it did in this case.
We feel that this approach would be suitable in most cases of intraperitoneal bladder perforation during TURBT and would spare many patients an exploratory laparotomy. In those cases where there is a significant bowel injury the exact site should be identified with ease prior to an open or laparoscopic repair.

This complication occurs rarely so it is impossible to report on a case series. The adoption of this technique more widely should help evaluate its safety over time.

\section{Conclusion}

In this case, examination of the adjacent bowel with a 20F urethroscope passed through an intraperitoneal bladder perforation during TURBT saved the patient from a more invasive laparotomy or laparoscopic procedure. A more invasive procedure can be avoided without sacrificing thoroughness.

Competing interests: The authors declare no competing financial or personal interests.

This paper has been peer-reviewed.

\section{References}

1. Hall MC, Chang SS, Dalbagni G, et al. Guideline for the management of non-muscle-invasive bladder cancer (Stages Ta, Tl, and Tis): 2007 Update. J Urol 2007;178:2314-30. http://dx.doi.org/10.1016/j. juro.2007.09.003

2. Babjuk $M$, Burger $M$, Zigeuner $R$, et al. EAU guidelines on non-muscle-invasive urothelial carcinoma of the bladder: Update 2013. Eur Urol 2013;64:639-53. http://dx.doi.org/10.1016/i.eururo.2013.06.003

3. Clark PE, Agarwal N, Biagioli MC, et al. Bladder cancer. J Natl Compr Canc Netw 2013;11:446-75.

4. Traxer 0 , Pasqui $F$, Gattegno $B$, et al. Technique and complications of transurethral surgery for bladder tumours. BJU Int 2004;94:492-6. http://dx.doi.org/10.1111/j.1464-410X.2004.04990.x

5. Balbay MD, Cimentepe E, Ünsal A, et al. The actual incidence of bladder perforation following transurethral bladder surgery. J Urol 2005;174:2260-3. http://dx.doi.org/10.1097/01.ju.0000181811.61199.35

6. Summerton DJ, Kitrey ND, Lumen N, et al. EAU guidelines on iatrogenic trauma. Eur Urol 2012;62:628-39. http://dx.doi.org/10.1016/i.eururo.2012.05.058

7. May F, Schlenker B, Hofer B, et al. Laparoscopic repair of iatrogenic bladder perforation during transurethral bladder tumor resection: Case report and literature review. Indian J Urol 2013;29:61-3. http://dx.doi. org/10.4103/0970-1591.109988

8. Golab A, Slojewski M, Gliniewicz B, et al. Laparoscopy as a treatment for intraperitoneal bladder injury. Scand J Urol Nephrol 2003;37:339-41. http://dx.doi.org/10.1080/00365590310014779

9. Pansadoro $A$, Franco $G$, Laurenti $C$, et al. Conservative treatment of intraperitoneal bladder perforation during transurethral resection of bladder tumour. Urology 2002;60:682-4. http://dx.doi.org/10.1016/ S0090-4295(02)01843-5

Correspondence: Dr. R. John D’A. Honey, University of Toronto, Toronto, ON, Canada; honeyj@smh.ca 